\title{
The Application of Freehand Painting Techniques in Oil Painting Teaching
}

\author{
RONG-HUEI HWANG, Fuzhou University of International Studies and Trade, Fuzhou, \\ Fujian, 350202, China
}

\begin{abstract}
The freehand oil painting techniques to fuse the Chinese and western artistic spirit and creative consciousness could Show the traditional culture of the Chinese nation, and absorb the modeling principles of western painting, to create a strong flavor of the times and national temperament. This article appreciates the aesthetic characteristics of freehand oil painting works, and analyzes the relationship between freehand oil painting and traditional painting in teaching, to propose some suggestions for the application of freehand oil painting techniques in teaching.
\end{abstract}

KEYWORDS: Freehand technique; Oil painting; Art teaching

\section{Introduction}

After decades of development, China's oil painting teaching system has been gradually improved. However, the training methods of most institutions are mainly based on the realistic style of creative realism painting, but ignore the education and cultivation of the expression of the imaginary vocabulary in the development of contemporary Chinese society, which has made a deviation in the field of Chinese painting education. Therefore, strengthening the proportion of freehand technique in oil painting technique teaching, and actively promote teaching consciousness in teaching, should be paid more attention in teaching practice.

\section{Aesthetic Characteristics in Freehand Oil Paintings Works}

\section{A. Modern Cultural Aesthetics}

The essence of freehand painting is that it focuses on the expression of the artist's personal feelings. It focuses on the emotional sustenance of the depicted object, rather than the shape of things themselves. To discover the aesthetics of things from different angles, this form of painting not only inherits Chinese traditional culture, but also is an interpretation of the concept of modern culture.

$\mathrm{Su}$ Tianci was one of the most typical painters of Chinese freehand painting. On the basis of Chinese traditional art thought, he integrated his own unique understanding of freehand oil painting. For example, in his work "a year of green grass" as shown in Fig.1, which was created in his old age. The depiction of trees and meadows is not delicate enough, but the sight of the spring it expresses is very vivid. The rich picture language built by virtual relation and color makes the seemingly simple picture filled with unique details. 


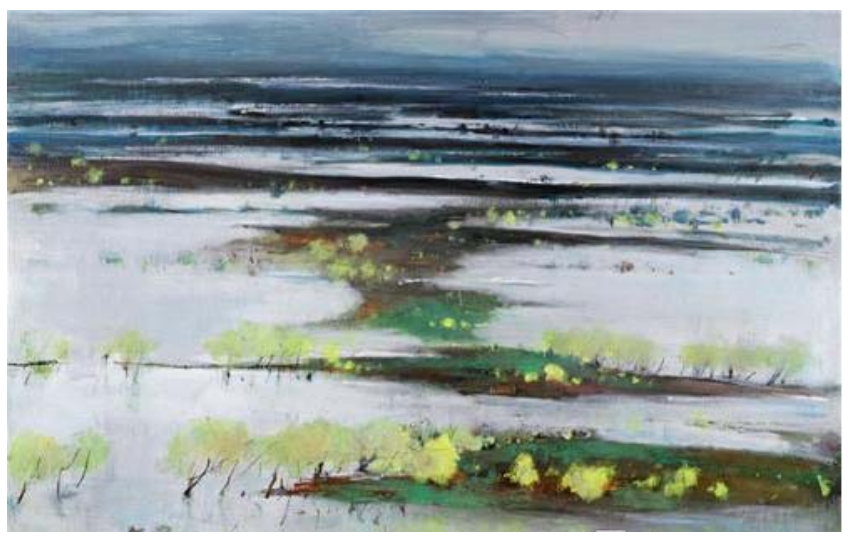

Figure 1. The work "a year of green grass" by Su Tianci

\section{B. Manifestations Aesthetics}

The manifestations of oil painting means that the artist hopes to discover and find the real self from the creative process, and focuses on expressing his inner feelings, rather than just concerning about the objective things themselves.

Oil painting is not a true reproduction of objective things, but based on the recording and expression of the artist's emotions, to create more excellent freehand oil paintings. Wassily Kandinsky thought that, the art of expressionism came into being because of the inner needs of man, including the speechless insight, intuition, basic emotion, and all things that make up spiritual life. In view of this, any oil painting works contain some characteristics of certain performance, which represents the artist's different feelings and interpretations of objective things.

\section{Modeling Aesthetics}

Lin Fengmina, as one of the earliest representative painters, has been trying to combine western painting with Chinese traditional painting. He boldly integrated his own life experience in painting, and formed a unique style of painting. Among his many paintings, "Explore" was the focus of everyone's attention, which mainly reflected the pursuit of artistic ideas and aesthetic values during his studies. It is worth mentioning that, in this work, the techniques of Chinese ink painting were heavily used, showing the characters in black and white tones.

Lin's another work "Human suffering" (as shown in Fig.2) also drew on the western composition and modeling features, although the artistic atmosphere of the works fully reveals the artistic style of the Chinese people. The work is relatively delicate in its representation of the human body, and it is easy to see that there is an inner force supporting the whole work. 


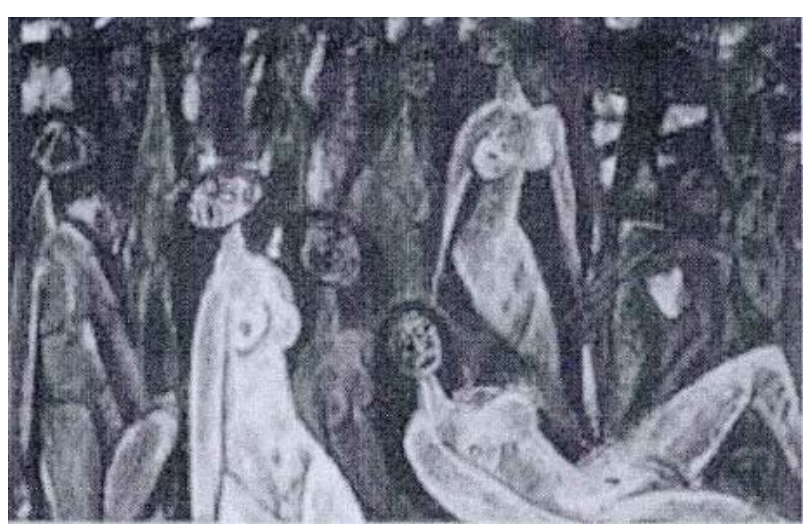

Figure 2. The work "human suffering" by Lin Mianfeng

\section{Relationship between Freehand Oil Painting and Traditional Painting in Teaching}

Today, domestic artists and art educators are exploring how to apply Chinese freehand painting techniques in teaching, to allow students to grasp and understand the style of freehand oil painting. Indeed, in the traditional art teaching in colleges and universities, some western classical forms and techniques of oil painting in the classical period or in modern times are followed, which pay more attention to the picture structure and the rich color change. Taking several typical painters as example, Bonnard was good at depicting cool colors and warm colors, and the complementary color in the picture of the performance of the contrast and induction; Van Gogh liked the strong expression of the contrast between the flow and the dazzling colors produced by the long box-shaped strokes; Cezanne often used the combination of the color structure position distribution and the picture emotional emotion of the picture object. While in China, oil painter Wu Guanzhong had suggested that oil painting would make the Chinese audience willing to accept, painters must combine the elegance of Chinese painting with the relatively abstract freehand style of oil painting. Wu's painting style tended towards freehand style. With a profound understanding of various styles of western modern art, we should also have the consciousness to immerse to Chinese traditional painting to find the painting factors, and continue to explore and practice the freehand painting style. The abstract oil painting style of painter Zhao Wuji was a faction, however he also sought the elements of painting in Chinese traditional paintings, with general and ethereal large color blocks, light and dark staggered changes and subtle colors, and he borrowed ancient Chinese hieroglyphics as a symbol to create empty spaces, so that the artistic conception of the whole picture conveys the connotation of Chinese aesthetics in the oriental mysterious symbolic sense.

The painting styles of these painters have directly or indirectly influenced the teaching practice of contemporary Chinese art education in a certain period, becoming a model for exploring the style of freehand brushwork between Chinese traditional painting and Western painting. In studying and teaching the style of freehand oil painting, it inevitably involves some of the ideas in Chinese traditional aesthetics. First of all, use artistic conception to guide students to understand freehand brushwork 
in oil painting. In traditional Chinese painting, artistic conception is intended to run through the whole painting, and is painted with an emotional visual image and imaginative objects in the virtual environment combined with the actual situation. In practice teaching in colleges and universities, to learn from the freehand painting techniques in traditional Chinese painting to guide oil painting teaching, would help provide more learning material in college painting teaching.

\section{Application of Freehand Oil Painting Techniques in Teaching}

(1) Pay attention to tone relationship

In the teaching of oil painting, when using freehand brushwork to deal with color language, we should pay attention to tone treatment. While in the painting process, learners should accurately grasp the color tendency of static objects, and determine the whole color tone, and show the big color of the whole painting. In the process of spreading the color, we should control the overall color relationship, to keep a good color freshness. When the large area of color blocks are well paved, combined with picture color effect, we need to deal with t e relationship between light and dark. It is important to point out that, the color tendency must be obvious. Generally speaking, images of high purity cannot be adjusted too much, but should put your eyes on the overall feeling of the picture, because only in this way can you get a good color atmosphere.

(2) Maintain color vision balance

In oil painting color teaching with freehand oil painting techniques, should pay attention to the balance of color vision. In the painting work, the expression effect of color space should have an organic connection with composition, artistic conception and color objects, and it needs to be set by color and color. After determining the base color of the picture, with the help of freehand painting techniques, the local relation of a picture and color relation of an image could be well portrayed. In the process of characterization, the balance of the physical structure, spatial perspective, color, light and shade, texture, and the environment of objects should be maintained and unified. After completing the characterization of objects, sometimes the overall color relationship is not coordinated. For this phenomenon, we need to adjust the picture as a whole, to find out the part that is out of touch with the whole, and then remodel it, so as to maintain overall picture balance and realize the unity of local change and overall harmony.

(3) Set the color structure properly

For the composition of color language in freehand oil painting, there are many theoretical sources in oil painting teaching in china. In ancient Chinese painting, people have established the color structure of black, white, red, yellow and green, but ignored the pursuit of objective solid color and light source color, so gradually formed the color structure of ink color, as a unique style of Chinese painting. Compare with western color structure, Chinese painting color presents a single feature, lack of coordinated control of color, which leads to color isolation in the painting, and cannot be effectively integrated with the overall picture. 
However, freehand oil painting techniques focuses on the combination of traditional Chinese cultural spirit, and the painters can parse, change, and combine the colors to create a unique style of work, according to their own personal sensory and visual experience. The application of freehand painting techniques does not mean giving up aesthetics, but to seek modern beauty in traditional aesthetics, so that show their artistic beauty.

\section{REFERENCE:}

[1] Surhone L M, Tennoe M T, Henssonow S F, et al. Oil Paint[J]. Poetry, 2010, 16(8):244-245.

[2] Bin H U, Art D O, University H N. Freehand painting and tender style_ reseach on the style of Ye Qianyu's paintings of dancers[J]. Journal of Anhui University of Science \& Technology, 2014.

[3] Yao-Hua W U. Modern Humanity Values of Freehand Painting in Chinese Paintings[J]. Journal of Nantong University, 2014.

[4] Shuyin L I. Reflection on Teaching Modules about Freehand Painting of Environmental Art Design[J]. Art \& Design, 2012.

[5] Xia W. The Analysis of Artistic Conception and Imagery of Freehand Painting[J]. Art \& Design, 2010.

[6] Zhang Y Q. The comparative study of sculpture freehand and painting freehand[J]. Journal of Nanchang College of Education, 2010.

[7] Hua X U. Freehand Style of Chinese Ceramic Painting[J]. China Ceramic Industry, 2012.

[8] Jiang Q H. Freehand Spirit in Chinese Oil-painting Language[J]. Hundred Schools in Arts, 2009. 